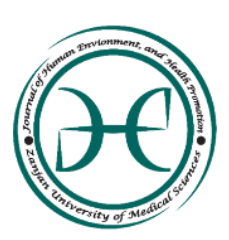

Journal of Human, Environment and Health Promotion

Journal homepage: www.zums.ac.ir/jhehp

\title{
Knowledge, Attitude and Practice of the Households about Prevention of Cutaneous Leishmaniasis, Iran, Shiraz at 2016
}

\author{
Tayebeh Rakhshani a, Seyyed Mansour Kashfi b, Mohammad Reza Ebrahimi c, Samira \\ Taravatmanesh ${ }^{\text {d,* }}$, Mostafa Rasheki ${ }^{\text {e }}$ \\ ${ }^{a}$ Basic Sciences in Infectious Diseases Research Center, Department of Public Health, Shiraz University of \\ Medical Sciences, Shiraz, Iran. \\ ${ }^{b}$ Research Center for Health Sciences, Department of Public Health, School of Health, Shiraz University of \\ Medical Science, Shiraz, Iran. \\ ${ }^{c}$ Department of Emergency Medicine, Iran University of Medical Science, Tehran, Iran. \\ ${ }^{d}$ Health Promotion Research Center, Department of Public Health, Zahedan University of Medical Sciences, \\ Zahedan, Iran. \\ ${ }^{e}$ Department of Public Health, Mashhad University of Medical Sciences, Mashhad, Iran.
}

*Corresponding author. E-mail address: Samira.taravat@yahoo.com

\section{A R T I C L E I N F O \\ Article history: \\ Received March 7, 2017 \\ Accepted April 24, 2017}

Article Type:

Original Article

\begin{abstract}
A B S T R A C T
Background: The aim of this study was to investigate the effects of knowledge, attitude and practice of the households on the prevention and control Cutaneous Leishmaniasis. Methods: This study was a cross-sectional, analytical. The population consisted of the residents in the south of Shiraz. The sample size was 300 and they were selected randomly. For analyzed using the descriptive indices as well as in-depended T-test, chisquare test and ANOVA. The SPSS software 16 was used for analysis.

Results: The mean age of the participants was 36.1 \pm 13.6 . The mean and standard deviation scores of knowledge, attitude and practice were $16.85 \pm 3.5,34.38 \pm 6.43$ and 5.6 \pm 1.9 , respectively. Pearson correlation coefficient showed that the mean awareness $(\mathrm{r}=$ 0.13 , P-value $=0.02$ ) was more correlated with the mean practice compared to the mean attitude $(\mathrm{r}=0.17$, P-value $=0.00)$. However, both variables of knowledge and attitude had a significant relationship with practice $(\mathrm{p}$-value $=0.00)$.

Conclusion: Generally, the results of our study showed that the scores of knowledge and practice were lower than the mean score, and the attitude score was better than the two other scores.
\end{abstract}

\section{Keywords:}

Knowledge

Attitude

Practice

Cutaneous Leishmaniasis

Shiraz

\section{Introduction}

According to the report by the center of disease control in the Ministry of Health in Iran, the incidence of cutaneous leishmaniasis in 2013 in these provinces was as follows. Ilam (an incidence of (102.6 per 1000), Fars (86.7 per
1000) and Khorasan Razavi (63.9 per 1000) had the highest incidence of cutaneous leishmaniasis and Gilan with the minimum incidence $(0.01)$ was ranked the last [1]. The cutaneous leishmaniasis has always been considered in our national plans.

To cite: Rakhshani T, Kashfi SM, Ebrahimi MR, Taravatmanesh S, Rasheki M. Knowledge, Attitude and Practice of the Households about Prevention of Cutaneous Leishmaniasis, Iran, Shiraz at 2016. J Hum Environ Health Promot. 2017; 2(3):186-192. 
Despite the extensive efforts and national and international investments, the disease has not only been eradicated, but with the emergence of new centers, it has attracted an important part of the health, political and social activities [2]. It also causes the economic, social and psychological problems and imposes an irreparable damage to the communities [2]. For these reasons, it is considered as one of the important diseases in terms of controlling and fighting [2]. Iran is one of the countries in the Eastern region of Mediterranean where the prevalence of the cutaneous leishmaniasis is high so that it is one of the top six countries in the world in terms of the prevalence of this disease and every year about 30,000 cases of the cutaneous leishmaniasis are reported in Iran [3-6]. However, according to the available research, the actual number of the cases is 4 to 5 times as much as the available statistics [3]. One of the most effective ways of reducing the prevalence of cutaneous leishmaniasis is to teach the people living in the endemic areas how to prevent the disease. In order to achieve this goal we should improve the awareness, the attitude and the performance of the risk group or the group that plays a major role in training and educating the community [7].

Furthermore, several studies conducted on controlling the leishmaniasis vectors have emphasized on the importance of health education and the community involvement [7]. For effective education, the current status needs to be examined exhaustively [3]. The results of the study by Haghpanah et al showed that the level of awareness about the cutaneous leishmaniasis in the endemic areas is very low [8]. The findings of the study by Saberi et al suggested that the health education for people is one of the most effective strategies to prevent the cutaneous leishmaniasis.

To provide the people with a better education, it is essential to assess their knowledge, attitude and performance before starting the task [8-10].

Various studies have shown that people's awareness of this disease is not desirable [7].

Given the importance of cutaneous leishmaniasis, and despite the efforts of the World Health Organization for the prevention of the disease, the therapeutic approach to the disease is dominant and there is no awareness about the importance of the health education and the health promotion for the prevention of leishmaniasis.

There are also important mental health problems among the people suffering from this disease and some examples are needed to be provided: In Afghanistan, those women with the cutaneous leishmaniasis are not allowed to touch their children, and young women with cutaneous leishmaniasis do not have the right to marry. The present study aimed to assess the knowledge, attitude and the practice of the households living in the south of Shiraz towards cutaneous leishmaniasis and controlling it so that we can identify the preventive practices of the families in order to achieve the importance of health education and health promotion to improve the knowledge and awareness of the families as some basic strategies for the management of Cutaneous Leishmaniasis.

\section{Materials and Methods}

This study was a cross-sectional study conducted on the household living in the south of Shiraz city at 2016. The study population consisted of the households living in the south of Shiraz who were selected randomly. Selecting the individuals to participate in the study was based on a random selection. An interviewer randomly choosed the desired homes, and after that the questionnaire of the study was completed. The sample size was estimated to be 300 according to the previous studies and the Krejcie-Morgan standard table. The study sampling was as a random sampling frame. There was no limitation to participate in this study. The individuals who wanted to complete the questionnaire attended the location and interviewed with the heads of the households and the questionnaires were completed in the presence of the interviewers. The data collection tool was a researcher-made questionnaire which was completed by the research units and also, the trained research assistants without mentioning the names and after getting the consent of the subjects. The questionnaires consisted of two parts: personal characteristics (6 questions about age, the level of 
education, family size, job, history of cutaneous leishmaniasis, hearing the name of the disease) and the questions related to awareness, knowledge and attitude.

There were a total of 10 questions about the awareness (including awareness about leishmaniasis, its treatment, transmission of the disease and its symptoms). The minimum obtained score was 10 and the maximum was 40. Eight questions were related to attitude (the participants' attitudes towards the mental illness caused by the remained wound and different ways to prevent the disease, etc).

The minimum and maximum obtained scores were 8 and 32, respectively. Finally, there were 9 questions related to their practice (in terms of the households' performance to prevent the mosquito bites and cutaneous leishmaniasis). The minimum and maximum obtained scores were 9 and 36, respectively. To determine the content validity of the data collection, some tools such as the literature reviews, books and the expert's comments were used. The reliability of the questionnaires was confirmed by the Cronbach's alpha coefficient $(\alpha=0.74)$.

For this study, given the main goals, after getting the approval by the Ethics Committee of Shiraz University of Medical Sciences, we referred to the households living in the southern areas of Shiraz and got their oral consent. The patients were also assured that their information contained in the questionnaires would be kept confidential and their names would not be mentioned. In this way, the required data were collected. Once the data were collected and sorted, they were entered to the SPSS files and analyzed using the following descriptive indices: mean, median, standard deviation and t-test, chi-square test and ANOVA. The SPSS version 16 was used for the analysis. The Ethic Committee of Shiraz University of Medical Sciences approved the study protocol (date, 1395-05-20; ID, 94-01-4311246).

\section{Results and Discussion}

Overall, 300 patients were enrolled in this study. The mean age of the participants was $36.1 \pm$ 13.6 and they were at the age range of 14 to 73 years old. Table 1 describes the basic characteristics of the participants. Out of the 283 study participants, $94.3 \%$ were familiar with the cutaneous leishmaniasis.

The mean and standard deviation scores for knowledge, attitude and practice were $16.85 \pm 3.5$, $34.38 \pm 6.43$ and $5.6 \pm 1.9$, respectively (Table 2).

The Pearson correlation coefficient showed that the mean of knowledge $(\mathrm{r}=0.13, \mathrm{P}$-value $=0.02)$, attitude $(\mathrm{r}=0.17, \mathrm{P}$-value $=0.00)$ was correlated with the mean practice but both had a weak correlation. However, both knowledge and attitude had a significant relationship with practice ( $\mathrm{p}$ value $<0.001$ ).

To determine the relationship between the demographic variables and the mean knowledge, attitude and practice, ANOVA, as an Independent T-Test, and the Pearson correlation were used and the results are shown in Table 3.

As it is shown in Table 3, the family history of the disease had a significant relationship with the knowledge score $(p$-value $=0.00)$. The education variable $(p$-value $=0.00)$ was significantly associated with the mean of attitude. None of the variables had a significant relationship with the mean score of practice ( $p$-value $\geq 0.05$ ) (Table 3 ).

The results of the multiple linear regression analysis showed that among the demographic variables, the household size (Beta $=0.13)$ was a stronger predictor for the awareness. The education (Beta $=0.24$ ) was a stronger predictor for the attitude and the family history of cutaneous leishmaniasis (Beta $=0.08)$ was a stronger predictor for the practice. The results of the multiple linear regression analysis are shown in Table 4.

The Knowledge regarding the attitude and practice of people that live in the Calaazar endemic area helped for the controlling and prevention of this disease. It is important to know the level of KAP in a community and improve it to 
a satisfactory level before introducing any disease control program in order to get the most support from the community. By acquiring these data a successful control program can be planned. Thus the current study was conducted to investigate the knowledge, attitudes and practices of the households living in the southern areas of Shiraz towards cutaneous leishmaniasis. The previous studies also examined the levels of knowledge, attitude and practice of the people for the cutaneous leishmaniasis $[11,12]$.

In general, the results of our study showed that the scores of knowledge and practice were lower than the mean score and the score of attitude was better than the two other scores. And compared to attitude, knowledge had a higher correlation with the participants' practice.

Table 1: Basic characteristics of the study population were interred in the study.

\begin{tabular}{|c|c|c|c|}
\hline Variable & & $\begin{array}{l}\text { Frequency / mean and } \\
\text { deviation }\end{array}$ & standard \\
\hline$\overline{\text { Age }}$ & & $36.1 \pm 13.6$ & \\
\hline \multirow[t]{4}{*}{ Job } & Employee & $51(17 \%)$ & \\
\hline & Worker & $(11 \%) 33$ & \\
\hline & housewife & $129(43 \%)$ & \\
\hline & Self-employed & $87(29 \%)$ & \\
\hline \multirow[t]{5}{*}{ Education } & illiterate & $40(13.3 \%)$ & \\
\hline & Primary & $38(12.7 \%)$ & \\
\hline & Junior & $73(24.3 \%)$ & \\
\hline & Diploma & $96(32 \%)$ & \\
\hline & Higher than diploma & $53(17.7 \%)$ & \\
\hline \multirow[t]{2}{*}{ Family size } & $4 \geq$ & $192(64 \%)$ & \\
\hline & $5 \leq$ & $108(36.1 \%)$ & \\
\hline \multirow[t]{2}{*}{ Family history of leishmaniasis } & Yes & $179(58.7 \%)$ & \\
\hline & No & $121(41.3 \%)$ & \\
\hline
\end{tabular}

Table 2: Mean scores of knowledge, attitude and practice of the study participants.

\begin{tabular}{lcccc}
\hline variable & $\begin{array}{c}\text { The mean and standard } \\
\text { deviation }\end{array}$ & $\begin{array}{c}\text { Minimum obtained } \\
\text { score }\end{array}$ & $\begin{array}{c}\text { Median obtained } \\
\text { score }\end{array}$ & $\begin{array}{c}\text { Maximum } \\
\text { obtained score }\end{array}$ \\
\hline Knowledge & $16.85 \pm 3.5$ & 10 & 40 & 32 \\
Attitude & $23.38 \pm 6.43$ & 8 & 21 & 36 \\
Practice & $5.6 \pm 1.9$ & 9 & 17 \\
\hline
\end{tabular}


Table 3: The relationship between the basic variables of the participants and the mean scores of knowledge, attitude and practice of women.

\begin{tabular}{lcccccc}
\hline variable & \multicolumn{2}{c}{ knowledge } & \multicolumn{2}{c}{ attitude } & \multicolumn{2}{c}{ practice } \\
\cline { 2 - 7 } & $\mathrm{Z}, \mathrm{t}, \mathrm{r}, \mathrm{F}$ & $\mathrm{P}$ value & $\mathrm{Z}, \mathrm{t}, \mathrm{r}, \mathrm{F}$ & $\mathrm{P}$ value & $\mathrm{Z}, \mathrm{t}, \mathrm{r}, \mathrm{F}$ & $\mathrm{P}$ value \\
\hline Age & 0.07 & 0.18 & -0.09 & 0.1 & 0.04 & 0.47 \\
Job & 1.74 & 0.14 & 0.48 & 0.75 & 0.76 & 0.56 \\
Education & 0.37 & 0.89 & 3.34 & 0.00 & 1.03 & 0.4 \\
Family size & 0.12 & 0.02 & -0.07 & 0.2 & -0.17 & 0.76 \\
Family history of & -3.5 & 0.00 & 1.21 & 0.22 & 0.008 & 0.99 \\
leishmaniasis & & & & & & \\
\hline
\end{tabular}

Table 4: Results of the multiple linear regression analysis of the basic variables of the study participants with the mean scores of knowledge, attitude and practice of the participants.

\begin{tabular}{lccccccccc}
\hline variable & \multicolumn{3}{c}{ knowledge } & \multicolumn{3}{c}{ attitude } & \multicolumn{3}{c}{ practice } \\
\cline { 2 - 9 } & Beta & $\mathrm{t}$ & $\mathrm{P}$ value & Beta & $\mathrm{t}$ & $\mathrm{P}$ value & Beta & $\mathrm{t}$ & P value \\
\hline Age & -0.04 & -0.63 & 0.52 & -0.14 & -1.9 & 0.04 & 0.02 & 0.29 & 0.77 \\
Job & -0.13 & -2.35 & 0.01 & -0.04 & -0.68 & 0.49 & -0.07 & -1.25 & 0.21 \\
Education & -0.02 & -0.44 & 0.65 & 0.24 & 3.81 & 0.000 & -0.09 & -1.49 & 0.13 \\
Family size & 0.13 & 1.81 & 0.07 & -0.08 & -1.17 & 0.24 & -0.09 & -1.22 & 0.22 \\
Family history & 0.04 & 0.72 & 0.46 & -0.02 & -0.42 & 0.67 & 0.08 & 1.47 & 0.14 \\
of leishmaniasis & & & & & & & & & \\
\hline
\end{tabular}

The findings of the present study indicated that the knowledge of the participants in the study was below average and this was consistent with the findings of previous studies $[13,14]$ but it was not consistent with the study by Alemu [15]. Low awareness of the people about leishmaniasis is a serious alarm due to the rising trend of the disease in recent years and also, the serious and close attention of the Ministry of Health and universities of Medical Sciences on leishmaniasis is requured. Hence, having full awareness is the first and the most basic step for any practices to have adequate and right information. If people's awareness is increased through the effective training methods, their attitude will improve as a result of their improved awareness.

The findings of our study in terms of the participants' attitudes showed that the attitude scores were close to average. Despite the low scores of knowledge, the attitude scores of the participants in our study were better. These findings are consistent with those of the study by Niknami et al [16] but they are not consistent with those of Alemu [15, 17].

The findings of our study also showed that the participants' practice scores were low and they were consistent with the study by Alemu [17]. The low scores of practice indicated that the health researchers and policymakers had to adopt the practice change strategies to help for the improvement of the practice. Understanding the beliefs and practices of people is a pivotal step in the successful implementation of the cutaneous Leishmaniasis control activities in Cutaneous Leishmaniasis -endemic areas.

Among the demographic variables entered into the study, the history of cutaneous leishmaniasis 
had a significant relationship with the individuals' knowledge. In families that already had a member with leishmaniasis, having knowledge about the disease was higher. The education variable had a significant relationship with the people's attitude scores and none of the initial variables had a significant relationship with the practices of the study participants.

The study by Al-Jawabreh et al demonstrated that the education had a significant relationship with the people's knowledge of Leishmaniasis and fewer cases of the disease were found among the people with higher education [18].

Among the variables that were investigated, the family size was a stronger predictor for knowledge, the education was a stronger predictor for attitude, and the history of Leishmaniasis was a stronger variable for the practice of the participants in the study.

\section{Strength and Limitations}

This study had some strengths and limitations: the strengths were the larger sample size and the investigation of the relationship between different variables. One of the limitations of the present study was that this study was a cross-sectional and descriptive. Since the data collection tool in this study was a questionnaire, the possible matching of the data to the other regions had to be done with caution.

\section{Conclusion}

Due to the low levels of the participants' knowledge about leishmaniasis and the ways to prevent it, and taking into account its education as an effective method in improving knowledge, it is recommended to do educational planning to improve the knowledge of the individuals who are at risk in the infected areas. The results of this study can help the health authorities for better implementation of the programs related to the control of cutaneous Leishmaniasis in Iran. Moreover, the findings of this study can be used for proposing a culturally sensitive and appropriate plan for the prevention and control of Cutaneous Leishmaniasis in these areas.

\section{Acknowledgement}

Hereby, all the people who participated in this study and made possible the implementation of the present project are warmly appreciated.

\section{Conflict of interest}

None declare.

\section{References}

1. Singh SP, Reddy DCS, Mishra RN, Sundar S. Knowledge, Attitude, and Practices Related to Kala-Azarin a Rural Area of Bihar State, India. Am J Trop Med Hyg. 2006; 73(5): 505-508.

2. Kazemi B, Bahrami A, Mousavi GA, Ramezani Y, Fereydooni M, Parsa N, et al. Epidemiological Study of Cutaneous Leishmaniasis in Aran and Bidgol from April to September 2009. Feyz, Kashan Univ Med Sci Health Serv. 1390; 15(3): 254-258.

3. Rahaei Z, Heshmati H, Hazavehei MM, Hasanzadeh A. Relationship between Educational Practice of Volunteer Health Workers and Preventive Behavior of Household Sunder their Coverage Regarding Cutaneous Leishmaniasis based on the Basef model in Yazd City, Iran. Sci J Sch Public Health Institute Public Health Res. 2011; 9(1): 77-85. [In Persian].

4. Noorpisheh S, Naghizadeh MM, Nikrouz L. A Study on the Life Quality of Patients Suffering from Leishmaniasis. JFUMS. 2013; 3 (2): 155162.

5. Ahmadi N, Ghafarzadeh M, Jalali Galosang A, Hjolami Parizad E. An Epidemiological Study of Cutaneous Leishmaniasis with Emphasis on Incidence Rate in Kashan, Isfahan Province. $J$ Ilam Univ Med Sci. 2013; 21 (2): 1-9.

\section{Asilian A, SadeghiNi A, Joeme SM, Fazlullah}


S. Effect of Permethrin Clothing Treatment of Cutaneous Leishmaniasis Disease Prevention Clinical Trial is a Randomized, Double-Blind. $J$ Diesese Skin. 2002; 6(2): 25-29.

7. Ahmadi NA, Ghafarzadeh M, Jalali Galoosang A. En Epidemiological Study of Cutaneous Leishmaniasis with Emphasis on Incidence Rate in Kashan, Isfahan Province. Scientific J Ilam Univ Med Sci. 2012; 22(2): 934-26.

8. Haghpanah B, Javadi A, Shadzi S, Solomon B, Yadollahi MS. Performance Training to Volunteers in Promoting Women's Awareness about the Prevention of Leishmaniasis. Res Med Sci. 1996; 5(4): 294-298.

9. Alvar J, Velez IND, Bern C, Herrero M, Desjeux P, Cano J, et al. Leishmaniasis Worldwide and Global Estimates of Its Incidence. PLoS One. 2012; 7(7): e35671.

10. Nejati J, Mojadam M, Hanafi Bojd AA, Keyhani A, Habibi Nodeh F. An Epidemiological Study of Cutaneous Leishmaniasis in Andimeshk (2005-2010). J Ilam Univ Med Sci. 2014; 21 (7): 94-101.

11. Abazid N, Jones C, Davies CR. Knowledge, Attitudes and Practices about Leishmaniasis among Cutaneous Leishmaniasis Patients in Aleppo, Syrian Arab Republic. East Mediterr Health J. 2012; 18(1): 7.

12. Sarkari B, Qasem A, Shafaf MR. Knowledge, Attitude, and Practices Related to Cutaneous Leishmaniasis in an Endemic Focus of Cutaneous Leishmaniasis, Southern Iran. Asian Pac J Trop Biomed. 2014; 4(7): 566-9

13. López-Perea N, Sordo L, Gadisa E, Cruz I, Hailu T, Moreno J, et al. Knowledge, Attitudes and Practices Related to Visceral Leishmaniasis in Rural Communities of Amhara State: A Longitudinal Study in Northwest Ethiopia. PLoS Negl Trop Dis. 2014; 8(4): e2799.

14. Koirala S, Parija SC, Karki P, Das ML. Knowledge, Attitudes, and Practices about KalaAzar and its Sandfly Vector in Rural Communities of Nepal. Bull World Health Org. 1998; 76(5): 485.

15. Alemu A, Esmael N, Dessie Y, Hamdu K, Mathewos B, Birhan W. Knowledge, Attitude and Practices Related to Visceral Leishmaniasis among Residents in Addis Zemen Town, South Gondar, Northwest Ethiopia. BMC Public Health. 2013; 13(1): 382.

16. Niknami S. Basnef Assessment Model to Determine Factors in the Prevention and Control Ofkala-Azar Disease and Providing a Appropriate Model. PhD Thesis. Tehran: Tarbiate Modares; 1994. [In Persian].

17. Ruoti M, Oddone R, Lampert N, Orue E, Miles MA, Alexander N, et al. Mucocutaneous Leishmaniasis: Knowledge, Attitudes, and Practices among Paraguayan Communities, Patients, and Health Professionals. J Trop Med. 2013; 2013: 538629.

18. Al-Jawabreh A, Barghuthy F, Schnur LF, Jacobson RL, Schonian G, Abdeen Z. Epidemiology of Cutaneous Leishmaniasis in Theendemic Area of Jericho, Palestine. East Mediterr Health J. 2003; 9: 805-815. 